\title{
Los escritos de Max Weber en español inventario bibliográfico
}

\section{Nota introductoria}

Esta bibliografía no pretende ser exhaustiva. Las múltiples y repetidas traducciones de Weber se hallan dispersas en revistas y casas editoriales del mundo hispano de difícil consulta por parte de los compiladores. Un mismo libro ha sido vertido al castellano a uno y otro lado del Atlántico y en ocasiones su difusión ha sido muy restringida. Esta contrariedad se hace todavía más abrumadora cuando se quiere hacer un inventario de los ensayos y artículos del sociólogo alemán divulgados en periódicos y revistas de uno y otro país. Allí las publicaciones periódicas apenas circulan y muchas de ellas carecen de Índices que permitan la búsqueda de materiales acumulados a lo largo de los años. A todo esto se suma la precariedad de las bibliotecas y centros de documentación de América Latina y España.

No obstante los desalientos que esta dispersión deja en el compilador más dedicado, creemos que el presente inventario es bastante completo en lo que respecta a los libros ya los trabajos sueltos de Weber reunidos en volúmenes compactos. Una mirada superficial muestra al momento que lo esencial de su obra se encuentra en español y que sólo falta por trasladar algunos libros de juventud, la correspondencia, los escritos periodísticos, unas cuantas reseñas e intervenciones públicas y uno que otro texto de historia antigua. Se debe subrayar, además, que el castellano fue la primera lengua extranjera que conoció una versión completa de Economía y sociedad, la obra de mayor aliento teórico de Weber. Si bien esto fue en su momento una adquisición espiritual de primer orden, con el paso de los años se ha hecho vieja y en muchos casos inadecuada. Cuando el libro apareció en español en 1944 en las prensas del Fondo de Cultura Económica de México, los estudios sobre Weber apenas comenzaban y el establecimiento del texto original era aún problemático (como todavía lo sigue siendo). La traducción de algunos conceptos era vacilante y la ausencia de un glosario y de comentados idóneos sobre pasajes oscuros, impedían la comprensión adecuada de una obra compleja por parte de una audiencia intelectualmente desarmada. Esto ha hecho que el colosal esfuerzo de don José Medina Echavarría y sus asociados deba ser revisado en los próximos años, sin menoscabo alguno de su empeño pionero y de su contribución al desarrollo de las ciencias sociales hispanoamericanas. El forzoso trabajo de depuración y análisis deberá realizarse teniendo en cuenta las lecciones de las versiones inglesas, francesas e italianas y los comentarios de los responsables de la edición de las obras completas de Weber en alemán. Y como se desprende del presente inventario, esta labor ya comienza a manifestarse, especialmente en España, país donde se asiste a un renovado interés por la obra del autor de Economía y sociedad*

\footnotetext{
* El texto de Economía y sociedad, tantas veces reimpreso por el Fondo de Cultura Económica, tendrá que afrontar en el futuro correcciones no sólo de traducción, de fijación y organización interna de capítulos y subcapítulos, sino también de explicación de pasajes ambiguos, de registro de posibles variantes y de cubrimiento de graves y molestos descuidos en la edición. Veamos un ejemplo. Entre las páginas 1010 y 1013 — en la sección dedicada a la dominación no legítima, tradicionalmente conocida como "La ciudad"-, los encargados de la edición mexicana han dejado, reimpresión tras reimpresión, un incómodo empastelamiento no siempre fácil de descubrir por parte del lector (La nueva versión de La ciudad, una pieza central en el pensamiento de Weber. publicada por ediciones La Piqueta de Madrid en 1987, ha remediado en buena hora esta obstinada desidia de los editores mexicanos).

Algo similar ocurre con la edición de la Historia económica general. El Fondo de Cultura Económica se ha negado persistentemente a publicar el prólogo de los editores originales — los señores Sigmund Hellmann y Melchior Palyi- y a hacer los ajustes necesarios a partir de la tercera edición alemana de 1958 a cargo de Johannes Winckelmann. En las notas introductorias de estos editores, se describe el estado de los apuntes y de los cuadernos de los estudiantes que sirvieron de base para ordenar el contenido de las conferencias de Weber en Munich en 1919 y 1920. Lo que hoy conocemos como la Historia económica general se extrajo de estos manuscritos, dando lugar a un texto que "si Weber hubiera gozado de una vida más larga, no habría presentado al 
Para observar con mayor claridad la recepción de la obra de Weber en español, la siguiente bibliografía ofrece un orden cronológico particular. La fecha inicial registra la aparición de los textos en castellano y el año entre paréntesis señala la edición original en alemán. La distancia entre una y otra fecha sugiere la cercanía o lejanía de la llegada de Weber a Hispanoamérica, pero sobre todo, la evolución de los énfasis temáticos y de los intereses teóricos - manifiestos o latentes- de esta recepción a lo largo de 74 años. (Hasta donde tenemos noticia, la primera publicación española del sociólogo alemán se hizo en 1926).

Gonzalo Cataño

Libros

1942 (1923) Historia económica general, con un prefacio del traductor (México: Fondo de Cultura Económica), trad. de Manuel Sánchez Sarto. Existen numerosas reimpresiones.

1944(1922) Economía y sociedad, con una nota preliminar de J. Medina Echavarría (México:Fondo de Cultura Económica), 4 vols. Traducción de J. Medina Echavarría, J. Roura Parella, E. García Máynez, Eugenio Imaz y J. Ferrater Mora. En 1964 apareció la segunda edición aumentada con los cambios de la cuarta edición alemana de 1956 (existen numerosas reimpresiones de esta edición).

1955 (1904 y 1905) La ética protestante y el espíritu del capitalismo (Madrid: Revista del derecho privado), trad. de L. Legaz Lacambra. Segunda edición: Ediciones Península de Barcelona, 1969 (existen numerosas reimpresiones). Otra versión ha sido difundida por Premia Editora de México (1979) en su colección La Red de Jonás a cargo de J. Chávez Martínez.

1966 (1919) El sabio y la política (Córdoba, Arg.: Eudecor, 1966). Este volumen reúne las famosas conferencias, "La política como vocación" y "La ciencia como vocación", los textos de Weber más difundidos entre los lectores de América Latina y España. Aunque esta es la primera edición compacta de las conferencias, la versión de $\mathrm{F}$. Rubio Llorente de la editorial Alianza de Madrid, El político y el cient\{fico de 1967 con una introducción de Raymond Aron-, es quizá la que más ha llegado al mundo académico. Esto no debe llevar a olvidar, sin embargo, otras traducciones aparecidas a uno y otro lado del Atlántico. Sin pretender lograr un registro completo, podemos enumerar las siguientes:

M. Weber, Ensayos de sociología contemporánea (Barcelona: Martínez Roca, 1972). pp. 97-192, trad. del inglés por Mireia Bofill; M. Weber, Política y ciencia (Buenos Aires: La Pléyade, 1976), trad. de Carlos Contreras; M. Weber, El trabajo intelectual como profesión (Barcelona: Bruguera, 1983), trad. de A. Kovacsics Meszaros; y M. Weber, La ciencia como profesión — La política como profesión (Madrid: Espasa Calpe, 1992), en traducción de Joaquín Abellán. Esta versión viene acompañada de una introducción del traductor y de útiles orientaciones para el lector no familiarizado con la época y el vocabulario de Weber.

1971(1904 y 1917) Sobre la teoría de las ciencias sociales (Barcelona: Península). Trad. de M. Farber-Kaiser. Este volumen contiene dos trabajos: "La objetividad del conocimiento en las ciencias y en la política sociales" y "El sentido de la libertad de valoración en las ciencias sociológicas y económicas".

público o por lo menos no en la forma actual", según lo anotaron Hellmann y Palyi en el prólogo a la edición original alemana de 1923. (Los prólogos de los editores alemanes se pueden leer ahora en la revista Hojas Económicas, nueva época, No. 5, Bogotá, febrero de 1996, pp. 105- 14, en traducción de Udo F. Noormann y G. Cataño). 
1971 (1904-1917) Ensayos sobre metodología sociológica, con una introducción de Pietro Rossi (Buenos Aires: Amorrortu). Trad. de J. Luis Etcheverry. Este volumen contiene cuatro ensayos: "La objetividad cognoscitiva de la ciencia social y de la política social"; "Estudios críticos sobre la lógica de las ciencias de la cultura"; "Sobre algunas categorías de la sociología comprensiva" y "El sentido de la neutralidad valorativa en las ciencias sociológicas y económicas".

1972 (1906-1924) Ensayos de sociología contemporánea, con una introducción de Hans H.. Gerth y C. Wrigth Mills (Barcelona: Martínez Roca). Trad. del inglés de Mireia Bofill. Este volumen es una versión del From Mar Weber Essays in sociology, la popular compilación norteamericana de textos de Weber aparecida en Nueva York en 1946.

1977 ¿Qué es la burocracia? (Buenos Aires: La Pléyade). Trad. de Rufino Arar. Nueva versión de la sección de Economía y sociedad dedicada a la "Esencia, supuestos y desarrollo de la dominación burocrática".

1977 Estructuras de poder (Buenos Aires: La Pléyade). Trad. de Rufino Arar. Nueva versión de algunas partes de la secciones de Economía y sociedad dedicadas a "Las comunidades políticas"ya"La dominación carismática y su transformación".

1978(1966-1915) Sociología de la religión (Buenos Aires: La Pléyade). Trad. de Ariel Navarro. Este pequeño volumen contiene tres ensayos: "Contribución a la sociología de las religiones mundiales"; "Tipología de la renuncia religiosa al mundo" y "Protestantismo y capitalismo".

1981 (1891) Historia agraria romana (Madrid: Akal). Trad. de V. A. González. 1982(1895-1924) Escritos políticos, edición a cargo de José Aricó (México: Folios

Ediciones), 2 vols. Trad. de E Rubio Llorente, E. Molina y Vedia, Romeo Medina,

Adriana Sandoval y José Aricó. Compilación de 14 ensayos políticos, precedidos de una advertencia editorial y de una nota biográfica.

1983(1908) Influencia de la gran industria en el comportamiento de los trabajadores, con un prólogo de la traductora (Bogotá: Tercer Mundo). Trad. de Anita Weiss de Belalcázar.

1984 (1904-1922) La acción social: ensayos metodológicos, con una nota introductoria de Salvador Giner y J. F. Ivars (Barcelona: Península). Trad. de M. Faber-Kaiser y Salvador Giner. Contiene tres trabajos: la sección inicial de Economía y sociedad y los ensayos "Los juicios de valor en ciencia social" y "La objetividad del conocimiento en las ciencias y la política sociales".

1984-1988(1904-1919) Ensayos sobre sociología de la religión (Madrid: Taurus). 3 vols. Tlad. de José Almaraz, Julio Carabaña y Jorge Vigil. Compilación de las monografías y ensayos de Weber sobre sociología de la religión.

1985(1903 y 1908) El problema de la irracionalidad en las ciencias sociales, con un estudio preliminar de J.M. García Blanco (Madrid: Tecnos). Trad. de Lioba Simón y J. M. García Blanco. Contiene dos ensayos: "Roscher y Knies y los problemas lógicos de la escuela histórica de economía" y "La teoría de la utilidad marginal y la ley fundamental de la psicofísica".

1987 (1894 y 1896) La bolsa: introducción al sistema bursátil, con una introducción de la traductora (Barcelona: Ariel), traducida por Carme Madrenas.

1987(1921) La ciudad, con una presentación de L. Martín Santos (Madrid: La Piqueta), traducida por Julia Varela y F Alvarez-Uria. Nueva versión de la sección de Economía y sociedad dedicada a la "Dominación no legítima".

1991(1895-1918) Escritos políticos, con un estudio preliminar del traductor (Madrid: Alianza). Trad. de Joaquín Abellán. Contiene tres ensayos: "El Estado nacional y la política económica", "Parlamento y gobierno en una Alemania reorganizada" y "El socialismo". 
1994 (1908 y 1909) Sociología del trabajo industrial, con una presentación del traductor (Madrid: Trotta). Trad. de Joaquín Abellán. Contiene dos trabajos: "Introducción metodológica para las encuestas de la Asociación de Política Social sobre selección y adaptación de los obreros en las grandes fábricas" y "Psicofísica del trabajo industrial".

1997 Sociología de la religión (Madrid: Ediciones Itsmo, S. A.). Traducción y edición de E. Gavilán Domínguez. Conjunto de ensayos de sociología de la religión (incluye una nueva versión de la sección de Economía y sociedad dedicada a la "Sociología de la comunidad religiosa"). El volumen viene acompañado de una comprensiva introducción del traductor y de un orientador glosario del conspicuo lenguaje de Weber en asuntos religiosos.

2001(1907) La "superación" de la concepción de la historia de R. Stammler (Bogotá: Ediciones Nueva Jurídica). Con un "Estudio preliminar" de Oscar Julián Guerrero. Trad. de Oscar Julián Guerrero.

\section{Textos y ensayos sueltos}

1926(1896) "La decadencia de la cultura antigua", Revista de Occidente, tomo XII, No. 37, Madrid, julio. Reproducido en Selección y recuerdo de la Revista de Occidente (Madrid Revista de Occidente, 1950), vol. II, pp. 143-70, y en Marc Bloch et al., La transición del esclavismo al feudalismo (Madrid: Akal, 1975), pp. 35-37.

1959 (1919) "La ciencia como profesión vocacional", en J. T. Fichte et al., La idea de la universidad en Alemania (Buenos Aires: Suramericana), pp. 306-38. Trad. de Peter Heller.

1959 (1919) "La política como vocación”. Revista de Ciencias Políticas y Sociales, México, año V, No. 16 (pp. 243-74) y No. 17 (pp. 453-75). Trad. de Enrique González Pedrero.

1966 (1924) "Sobre la burocratización", en J. Peter Mayer. Mar Weber y la política alemana (Madrid: Instituto de Estudios Políticos), pp. 199-206. Trad. del inglés de A. Gil Lasierra. Texto de una intervención de Weber en la reunión de 1909 de la Asociación para la Política Social, publicado por primera vez en alemán en 1924. En América Latina se han difundido dos versiones adicionales: una en la revista Eco, No. 222, Bogotá, abril de 1980, pp. 604-09 (trad. del inglés de Gonzalo Cataño), y otra en M. Weber, Escritos políticos (México: Folios Ediciones, 1982), vol. II, pp. 46469 , en traducción de José Aricó.

1981 "La sociología de Simmel", Papers : Revista de Sociología, No. 5, Barcelona, pp. 147-51. Traducción de un texto inédito de Weber redactado hacia 1908. Una segunda versión, a cargo de F. Gil Villegas, se encuentra en la revista Sociológica, No. 1, México, 1986, pp.8I-85.

1986(1910) "La última palabra contra la crítica al espíritu del capitalismo", con una introducción de Wallace M. Davis. Sociología UN (publicación interna del Departamento de Sociología de la Universidad Nacional de Colombia). En mimeógrafo, septiembre, 44p. Traducido del inglés por Fernando Visbal.

1990(1908-1919) "El poder del Estado y la dignidad de la vocación académica", con una nota introductoria de G. Cataño. Revista Colombiana de Educación, No. 21, Bogotá, pp. 7-99. Trad. del inglés de Y. Ramírez Prado y Gonzalo Cataño. Compilación de artículos polémicos sobre asuntos universitarios.

1990(1892) "La situación de los trabajadores agrícolas de la Alemania al este del Elba: visión general", con una presentación de J. Carabañas Morales. Revista Española de Investigaciones Sociológicas, No. 49, Madrid, enero-marzo, pp. 223-55. Trad. de Christine Loffler y F. J. Noya Miranda. 
1995 (1965) "Una conversación entre Joseph Schumpeter y Max Weber", con una nota introductoria de Gerd Schroeter. Revista Colombiana de Sociología, nueva serie, vol. II, No. 2, pp. 97-103. Trad. de Femando Cubides.

1996(1923, 1927 y 1958) "Los prólogos de la Historia económica general de Max Weber", en Hojas Económicas, nueva época, Bogotá, No. 5, febrero, pp. 105-114. Trad. de Udo F. Noonnann y Gonzalo Cataño. Contiene los prólogos a las ediciones alemanas de Sigmund Hellmann y Melchor Palyi (1923) y de Johannes Winckelmann (1958), no incluidos en la versión castellana de la Historia económica general Trae, además, el "Prefacio" (1927) de Frank H. Knight a la edición inglesa del mismo libro.

1999(1910) "Sociología de la prensa", con una nota introductoria de Carlos Mosquera. Revista Colombiana de Educación, No. 38-39, Bogotá. Trad. de Carlos Mosquera. 2000(1920 y 1922) "Educación y formas de dominación", con una introducción de Gonzalo Cataño. Revista Colombiana de Educación, No. 40-41, Bogotá. Traducciones del inglés de Libardo González, Gonzalo Cataño y Carlos Mosquera.

Nota final: En Colombia existe una versión inédita, a cargo de Carlos Mosquera, de las críticas a Stamrnler, volumen que contiene los dos extensos artículos polémicos de Weber acerca de la obra del jurista alemán Rudolf Stammler, Economía y derecho según la concepción materialista de la historia, publicados en su Gesammelte Aufsätze zur Wissenschaftslehre (Compilación de ensayos sobre teoría de la ciencia) de 1922. 